\title{
Treatment of Enteric Fever with Pefloxacin for 7 Days versus 5 Days: a Randomized Clinical Trial
}

\author{
SERHAT ÜNAL,* MURAT HAYRAN, SERDAR TUNCER, DENIZ GÜR, \\ ÖMRÜM UZUN, MURAT AKOVA, AND H. ERDAL AKALIN $\dagger$ \\ Department of Internal Medicine, Section of Infectious Diseases, School of Medicine, \\ Hacettepe University, 06100 Ankara, Turkey
}

Received 16 February 1996/Returned for modification 2 April 1996/Accepted 24 September 1996

\begin{abstract}
In this prospective study of enteric fever, 22 patients received $400 \mathrm{mg}$ of pefloxacin twice daily for 5 days (group A) and 24 received $400 \mathrm{mg}$ of pefloxacin twice daily for 7 days (group B). Causative microorganisms were Salmonella typhi (8 in group A, 11 in group B) and Salmonella paratyphi B (14 in group A, 13 in group B). The clinical cure and bacterial eradication rates were $96 \%(21$ of 22$)$ in group $A$ and $100 \%$ in group $B$. In conclusion, 5-day oral administration of pefloxacin was as effective as 7-day treatment of enteric fever caused by Salmonella spp.
\end{abstract}

Enteric fever is a serious systemic infection and still common in most developing countries. It is caused by Salmonella spp., usually Salmonella typhi. At present, chloramphenicol, ampicillin, or trimethoprim-sulfamethoxazole (TMP-SMX) are the first-choice antibiotics for the treatment of enteric fever (7). However, increasing resistance to these drugs has necessitated the search for alternative drugs (4). In addition, the traditional antimicrobial agents must be given for 14 days to reduce the high relapse rates. This poses an important problem in patients' compliance to treatment as well as an economic burden, particularly in developing countries. Therefore, efforts should be directed to developing new antimicrobial agents and shortening the duration of treatment.

In vitro susceptibility tests have shown that fluorinated quinolones have excellent activity against $S$. typhi and Salmonella paratyphi, including the strains resistant to chloramphenicol, ampicillin, and TMP-SMX $(6,9)$. These agents also achieve good intracellular concentrations, particularly in phagocytes, and adequate levels in tissues, bile, and feces. The quinolone antibiotics, including ciprofloxacin, ofloxacin, pefloxacin, and fleroxacin, have been used in several clinical trials with a great success rate (3). Although a limited number of successful treatments as short as 2 or 3 days have been reported, the optimal duration of treatment remains to be determined $(17,19)$.

Here we report the comparative results of a 7-day versus a 5-day treatment of enteric fever with oral pefloxacin in an open, prospective, randomized study.

Forty-six patients (22 males, 24 females) hospitalized between June 1992 and October 1994 for enteric fever were randomized to receive pefloxacin for 5 days (group A) or 7 days (group B). All patients with febrile disease and at least one positive blood and/or bone marrow culture for Salmonella spp. were included. Patients under 16 years of age, pregnant and lactating women, those with jaundice and hepatic failure, and the patients who had received any antibiotic within the last 2 weeks were excluded. The daily dose of pefloxacin was 400

\footnotetext{
* Corresponding author. Mailing address: School of Medicine, Department of Internal Medicine, Section of Infectious Diseases, Hacettepe University, 06100, Ankara, Turkey. Phone: 90-312-3111271. Fax: 90-312-4358423. Electronic mail address: su04-k@servis2.net.tr.

$\dagger$ Present address: Pfizer İlaçları A. Ş. 80840 Ortaköy-İstanbul, Turkey.
}

mg twice daily (BID) perorally in both groups, and the therapy was started as soon as the culture results were obtained.

Fever, gastrointestinal complaints (abdominal pain, nausea, vomiting, diarrhea, and constipation), anorexia, malaise, prostration, and headache were assessed as clinical symptoms. All patients underwent a complete physical examination. Urinalysis, complete blood count with differential, prothrombin times, and biochemistry profiles were determined, and radiographic tests were performed as needed. Hematological and biochemical parameters were repeated on the second or third day of therapy and 2 or 3 days after the completion of therapy. Three sets of blood, bone marrow, urine, and stool cultures were obtained on the first day of admission to the hospital. Blood, urine, and stool cultures were repeated 2 days after the treatment and 1 month after the completion of therapy. The isolated Salmonella strains were identified by standard biochemical tests and agglutination with salmonella antisera (Wellcome Diagnostics). Antibiotic susceptibilities were tested by a standard broth microdilution technique (14).

The physical examination was repeated, and fever, digestive, and neurologic symptoms were recorded daily. Fever was considered to be cleared if the patient's temperature was $<37.5^{\circ} \mathrm{C}$ for at least $48 \mathrm{~h}$. Clinical cure was defined as complete disappearance of clinical symptoms under treatment and lack of relapse within 30 days after the treatment, and failure was defined as continuing or worsening of symptoms 7 days after treatment with pefloxacin. Relapse was present if the patient had similar signs and symptoms after apparently being cured within a month. Tolerance was considered excellent if there were no side effects, intermediate if the side effects did not require interruption of the treatment, and poor if side effects required the cessation of the treatment.

Data were analyzed by Student's $t$ test and chi-square test when applicable (Statistical Package for Social Sciences, SPSS version 5.01, 1992).

Twenty-two patients ( 9 males, 13 females) received $400 \mathrm{mg}$ BID of pefloxacin for 5 days in group A and 24 patients (13 males, 11 females) received $400 \mathrm{mg}$ BID of pefloxacin for 7 days in group B. The mean age was 24 years (range: 18 to 40 years) and 26 years (range: 18 to 68 years), respectively, for groups A and B. Demographic, clinical, and laboratory features of patients in both groups were similar (Table 1).

Bone marrow and/or blood cultures were positive for Sal- 
TABLE 1. Demographic, clinical, and laboratory features of patients

\begin{tabular}{|c|c|c|}
\hline Parameter & $\begin{array}{l}\text { Group A } \\
(n=22)\end{array}$ & $\begin{array}{l}\text { Group B } \\
(n=24)\end{array}$ \\
\hline No. of males/no. of females & $9 / 13$ & $13 / 11$ \\
\hline Age $(y r)($ mean + SD) & $24+7$ & $26+11$ \\
\hline Weight $(\mathrm{kg})($ mean $+\mathrm{SD})$ & $59.5+15.2$ & $61.7+13.0$ \\
\hline $\begin{array}{l}\text { Admission temperature }\left({ }^{\circ} \mathrm{C}\right) \\
(\text { mean }+\mathrm{SD})\end{array}$ & $39.5+0.6$ & $39.5+0.6$ \\
\hline $\begin{array}{l}\text { Fever duration before hospitalization (days) } \\
\quad(\text { mean }+ \text { SD) }\end{array}$ & $12.4+8.7$ & $12.4+9.9$ \\
\hline No. with hepatomegaly & 4 & 3 \\
\hline No. with splenomegaly & 12 & 13 \\
\hline No. with leukocytes $<4,000 / \mathrm{mm}^{3}$ & 7 & 14 \\
\hline ALT and/or AST elevation on admission ${ }^{a}$ & 12 & 13 \\
\hline \multicolumn{3}{|l|}{ Site of organism isolated } \\
\hline Blood & 14 & 15 \\
\hline Bone marrow & 12 & 12 \\
\hline Both & 4 & 3 \\
\hline Stool and one of the above & 1 & 2 \\
\hline \multicolumn{3}{|l|}{ Causative organism } \\
\hline S. typhi & 8 & 11 \\
\hline S. paratyphi A & & \\
\hline S. paratyphi B & 14 & 13 \\
\hline \multicolumn{3}{|l|}{$\begin{array}{l}\text { Multiresistant organisms }{ }^{b} \text { (no. of strains) } \\
\text { resistant to: }\end{array}$} \\
\hline Pefloxacin & 0 & 0 \\
\hline Chloramphenicol & 5 & 5 \\
\hline Ampicillin & 11 & 11 \\
\hline TMP-SMX & 6 & 8 \\
\hline \multicolumn{3}{|l|}{$\operatorname{MIC}_{90}(\mu \mathrm{g} / \mathrm{ml})^{c}$} \\
\hline Pefloxacin & 0.05 & 0.05 \\
\hline Chloramphenicol & 64 & 32 \\
\hline Ampicillin & 128 & 256 \\
\hline TMP-SMX & 64 & 64 \\
\hline
\end{tabular}

${ }^{a}$ ALT, alanine amniotransferase; AST, aspartate aminotransferase.

${ }^{b}$ Resistant to chloramphenicol, ampicillin, and TMP-SMX.

${ }^{c} \mathrm{MIC}_{90}$, MIC at which $90 \%$ of the organisms are inhibited.

monella spp. The causative microorganisms were $S$. typhi (8 in group A, 11 in group B) and $S$. paratyphi B (14 in group A, 13 in group B). The MIC at which $90 \%$ of the isolated organisms were inhibited by pefloxacin was $0.05 \mu \mathrm{g} / \mathrm{ml}$ (MIC range; 0.06 to $1 \mu \mathrm{g} / \mathrm{ml}$ ) in both groups. Six isolates (3 in group A and 3 in group B) were multiply resistant (resistant to chloramphenicol, ampicillin, and TMP-SMX).

All patients were clinically cured, and clinical response was obtained in 1 to 5 days after initiation of therapy in both groups. Bacteriological eradication rates were $96 \%$ (21 of 22) in group A and $100 \%$ in group B (Fisher's exact test; $P>0.05$; $95 \%$ confidence interval, 0.1321 to 88.467$)$. Control stool cultures remained negative 1 week and 1 month after the completion of therapy. Only one patient in group A relapsed symptomatically 26 days after the treatment. S. typhi with the same antibiotic resistance pattern was isolated from stool samples during the second episode for this patient.

Nausea and vomiting ( 3 patients in group A and 3 patients in group B) and increase in transaminases not exceeding twice the pretreatment levels (one patient in group B) were the only side effects noted. The outcome in both treatment groups are shown in Table 2.

The treatment of enteric fever is still challenging to most physicians because of increasing resistance rates to commonly used antibiotics including chloramphenicol, ampicillin, and TMP-SMX. Poor compliance, high relapse rates, and economical burden of long-term treatment are additional problems, especially in developing countries.
TABLE 2. Treatment results

\begin{tabular}{lcr}
\hline \multicolumn{1}{c}{ Parameter } & $\begin{array}{r}\text { Group A } \\
(n=22)\end{array}$ & $\begin{array}{r}\text { Group B } \\
(n=24)\end{array}$ \\
\hline $\begin{array}{l}\text { Mean day of disappearance of fever } \\
\text { (mean + SD) }\end{array}$ & $3.1+1$ & $3.4+1$ \\
$\quad$ & & \\
No. (\%) of patients with: & & \\
$\quad$ Clinical outcome & $21(96)^{a}$ & $24(100)$ \\
$\quad$ Cure & $1(4)$ & \\
$\quad$ Failure and/or relapse & $21(96)^{a}$ & $24(100)$ \\
Microbiologic eradication rate & $19(86.4)$ & $20(83.3)$ \\
$\quad \begin{array}{l}\text { Tolerance } \\
\quad \text { Excellent }\end{array}$ & $3(13.6)$ & $4(17.7)$ \\
$\quad \begin{array}{l}\text { Intermediate } \\
\text { Poor }\end{array}$ & & \\
\hline
\end{tabular}

${ }^{a} P>0.05$, Fisher's exact test; $95 \%$ confidence interval, 0.1321 to 88.467 .

Fluoroquinolones have been used for the treatment of enteric fever since the $1980 \mathrm{~s}$, and $100 \%$ cure rates were obtained with 14- to 15-day regimens of ciprofloxacin $(9,11)$, ofloxacin $(2,16)$, and pefloxacin $(1,8)$, which have not been achieved with standard drugs. In addition, since quinolones are intracellularly active drugs, they may have lower relapse rates in the treatment of typhoid fever. In the majority of previous studies with quinolones, no relapses were reported.

The major problem with the quinolones is their cost. Clinical trials with shorter durations of therapy were carried out to improve the cost-benefit values. Several trials with shortcourse (7 to 10 days) ciprofloxacin (15), ofloxacin (12), and pefloxacin (13) in typhoid fever revealed high cure rates (82 to $100 \%$ ) (10). Our previous experience in treating typhoid fever with a 10-day course of ofloxacin showed excellent results (100\% cure in 32 patients) (18). The present study showed that patients with enteric fever had rapid defervescence and high cure rates with even shorter duration of treatment ( 5 or 7 days) with oral pefloxacin. In a multicenter noncomparative study, Bryskier et al. reported a 99\% success rate in 106 patients with 5 days of ofloxacin treatment (5).

Although short-term treatment regimens have the advantage of reduced cost, improved patient compliance, and still high success rates, data on relapses are limited. In findings similar to those of our study, Waiz et al. reported no relapse in 30 patients with 7 days of pefloxacin treatment (20). These findings, however, should be interpreted with caution since the sample sizes of these studies are too small to draw a firm conclusion. There was only one relapse in 106 patients in the Bryskier group, but this study was an open, noncomparative trial (5). In a recent clinical study comparing 2 days of ofloxacin with 3 days of ofloxacin in 108 children with enteric fever, there was only one suspected relapse (19).

In conclusion, 5-day treatment of enteric fever with pefloxacin appears to be as effective as 7-day therapy. The efficacy of shorter courses ( 2 to 5 days) requires further evaluation in randomized clinical studies.

We gratefully acknowledge Eczacıbaş//Rhone-Poulenc A.Ş for supporting pefloxacin as the study drug.

\section{REFERENCES}

1. Ait-Khaled, A., L. Zidane, A. Amrane, and R. Aklil. 1990. The efficacy and safety of pefloxacin in the treatment of typhoid fever in Algeria. J. Antimicrob. Chemother. 26(Suppl. B):181-186.

2. Akhtar, M. A., K. A. Karamat, A. Z. Molit, A. Hashmi, and Q. M. Khan. 1989. Efficacy of ofloxacin in typhoid fever particularly in drug-resistant cases. Rev. Infect. Dis. 11(Suppl. 5):1193-1195.

3. Bergan, T. 1985. Pharmacokinetics of quinolones. Quinolones Bull. 1:2-3. 
4. Bryan, J. P., H. Rocha, and W. M. Scheld. 1986. Problems in salmonellosis: rational for clinical trials with newer betalactams and quinolones. Rev. Infect. Dis. 8:189-209.

5. Bryskier, A., A. Zribi, B. Ould Rouis, A. Kadio, and A. Fisch. 1992. Typhoid fever: five day therapy with ofloxacin, preliminary results (abstract), p. 223. Proceedings of the 4th International Symposium on New Quinolones, Munich.

6. Cristiano, P., and G. Morelli. 1989. Therapeutic role of fluoroquinolones in the therapy of typhoid fever (abstract). OR 9/6. Proceedings of the 1st Western Pacific Congress on Infectious Disease Chemotherapy, Kuala Lumpur, Malaysia.

7. Gilman, R.H. 1989. General considerations in the management of typhoid fever and dysentery. Scand. J. Gastroenterol. 24(Suppl. 169):11-18.

8. Hajji, M. N. El Mdagri, and M. Benbachir. 1988. Prospective randomized comparative trial of pefloxacin versus cotrimoxazole in the treatment of typhoid fever in adults. Eur. J. Clin. Microbiol. Infect. Dis. 7:361-363.

9. Limson, B. M. 1989. Use of quinolones in typhoid fever. Quinolones Bull. 5:17-19.

10. Limson, B. M. 1995. Short course quinolone therapy of typhoid fever in developing countries. Drugs 49(Suppl):27-29.

11. Limson, B. M., and R. T. Littaua. 1989. Efficacy and safety of ciprofloxacin in uncomplicated typhoid fever (letter). Infection 17:105-106.

12. Lo, W. L. 1988. Ofloxacin in the treatment of typhoid fever: a preliminary study. J. Antimicrob. Chemother. 21:681-682.

13. Loza, G. F. 1990. Pefloxacin in the management of typhoid fever. Int. J. Clin. Practice 27:19-21.
14. National Committee for Clinical Laboratory Standards. 1993. Methods for dilution antimicrobial susceptibility test for bacteria that grow aerobically. Approved standard M7-A3. National Committee for Clinical Laboratory Standards, Villanova, $\mathrm{Pa}$.

15. Nelwan, R. H. H., Hendarwanto, I., Zulkarnian, H. Yusuf; I. Supandiman, K. Soedin, and A. Syahroni. 1992. Recent results of short-course treatment of typhoid fever with ciprofloxacin (abstract). Proceedings of the 3rd Western Pacific Congress on Chemotherapy and Infectious Diseases Bali 5:20.04.

16. Peyramond, E., S. Tigaud, F. Lucht, J. M. Vedrinne, F. Salord, and J. L. Bertrand. 1986. Clinical evaluation of of ofloxacin in the treatment of various infections. Pathobiology 34:471-475.

17. Smith, M. D., N. M. Duong, N. T. T. Hoa, J. Wain, H. D. Ha, T. S. Diep N. P. J. Day, T. T. Hien, and N. J. White. 1994. Comparison of ofloxacin and ceftriaxone for short-course treatment of enteric fever. Antimicrob. Agents Chemother. 38:1716-1720.

18. Ünal, S., H. E. Akalın, D. Gür, and M. Baykal. 1991. Clinical efficacy of ofloxacin in the treatment of enteric fever, p. 306-307. European Journal of Clinical Microbiology Proceedings, 3rd International Symposium on New Quinolones.

19. Vinh, H. A., J. Wain, V. T. N. Hahn, C. N. Nga, M. T. Chinh, D. Bethell, N. T. T. Hoa, T. S. Diep, N. M. Dung, and N. J. White. 1996. Two or three days of ofloxacin treatment for uncomplicated multidrug-resistant typhoid fever in children. Antimicrob. Agents. Chemother. 40:958-961.

20. Waiz, A., A. M. Siddique, and M. Hossain. 1992. The efficacy and safety of pefloxacin in the treatment of typhoid fever (abstract), p. 220. Proceedings of the 4th International Symposium on New Quinolones, Munich. 